\title{
Effect on Birth Weight of Smoking in Pregnancy
}

\author{
Maj K R Young \\ MRCOG, RAMC
}

Senior Specialist in Obstetrics and Gynaecology

Royal Naval Hospital, Gibraltar

SUMMARY: Maternal cigarette consumption during pregnancy, and infant birth weight were assessed in 427 consecutive births at BMH Rinteln. Smokers comprised $46.1 \%$ of the mothers. Babies born to mothers whọ smoked were significantly lighter than those born to non-smoking mothers, regardless of birth ordera. Smoking mothers were disproportionately represented in the low birth weight group. (19 out of 24) Therg are clear implications for military obstetric and paediatric practice.

\section{Introduction}

In the calendar year 1979/80 at BMH Rinteln one hundred and seven low birth weight babies (under $2.5 \mathrm{~kg}$ ) were delivered. Ten of these were born to mothers transferred from other hospitals in late pregnancy because of the lack of neonatal paediatric facilities elsewhere, and these 10 cases were excluded from the figure. There were thus 97 low birth weight infants born to mothers for whom BMH Rinteln had antenatal responsibility. A retrospective study of the notes from these cases revealed that 51 of the mothers were smokers, 25 were non smokers and in 21 cases there was no record of smoking habit. Thus of those where smoking habit was recorded 51 out of 76 mothers $(67 \%)$ were smokers. Even if all those with unrecorded smoking habit were non smokers, well over half $(52.6 \%)$ of the mothers of low birth weight babies were smokers.

Crowdy and Lewthwaite ${ }^{1}$ have drawn attention to the changing smoking habits of young soldiers but nothing has been published about smoking habits of their wives. It was therefore decided to carry out a small prospective study to determine the incidence of smokers amongst the obstetric population and to assess the effect of smoking habit on birth weight.

\section{Patients and Methods}

The mothers of 427 consecutive singleton infants were interviewed within 24 hours of the birth. A smoker was defined as any patient having smoked after 12 weeks gestation. The interview was carried out in a non accusative manner at the bedside and a thoughtful assessment of average cigarette consumption was encouraged. Where possible the smoking habit at booking (recorded in the notes) was used to check the accuracy of statements made postpartum. The cigarette consumption, birth weight, birth order and estimated gestation were recorded The results were subjected to statistical analysis using the students ' $t$ ' test of significance.

\section{Results}

Smoking habit: Of the 427 mothers questioned $197(46.1 \%)$ were admitted smokers. Of कh smokers $57(28.9 \%)$ smoked less than 10 per dîn $99(50.2 \%)$ smoked between 11 and 20 cigareftes per day, and $41(20.8 \%)$ smoked more than $20 \%$

Of the 177 primigravidae, only $70(39.3 \%)$ nefres smokers, whilst $92(52.3 \%)$ of the 174 seculie gravid mothers smoked.

Birth weight by smoking habit: Table I shows the difference between mean birth weight for babies fog non smokers and smokers and for different level $\$$ of cigarette consumption. The difference betwee $\vec{F}$ non smokers and each group of smokers is sta 3 tistically significant. ( $\mathrm{P}$ is less than 0.01) There is no significant difference in birth weight betwee? different cigarette consumption groups.

Table II shows the effect of birth order and smokg ing on birth weight. There is no significant differs ence between the mean birth weight of babies in birth order one and birth order two and this is true regardless of whether the mother smokes. Howeveri within each birth order cohort there is a significan difference between mean birth weight for babies of smoking and non smoking mothers. For birth order $1 \mathbf{P}$ is less than 0.05 and for birth order $2 \mathrm{P}$ ig less than 0.01 .

Cigarette consumption and low birth weight There were 24 babies weighing less than $2.5 \mathrm{~kg}$ and the mothers of 19 of these were smokers. Of the low birth weight babies 14 were classed as pre term (less 
Table I

Mean birthweight against average daily cigarette consumption

\begin{tabular}{cccccc}
\hline Consumption & $\begin{array}{c}\text { Non-Smokers } \\
\mathbf{n}=\mathbf{2 3 0}\end{array}$ & $\begin{array}{c}\text { All Smokers } \\
\mathbf{n}=\mathbf{1 9 7}\end{array}$ & $\begin{array}{c}<\mathbf{1 0} \text { per Day } \\
\mathbf{n = 5 7}\end{array}$ & $\begin{array}{c}\mathbf{1 1 - 2 0} \text { per Day } \\
\mathbf{n}=\mathbf{9 9}\end{array}$ & $\begin{array}{c}>\mathbf{2 0} \text { per Day } \\
\mathbf{n}=\mathbf{4 1}\end{array}$ \\
$\begin{array}{c}\text { Mean } \\
\text { Birthweight }\end{array}$ & 3.306 & 3.127 & 3.054 & 3.167 & 3.131 \\
$(\mathrm{Kg})$ & & & & \\
\hline
\end{tabular}

Table II

The effect of birth order and smoking habit on birthweight

\begin{tabular}{|c|c|c|c|c|c|c|c|c|}
\hline Mean & $\begin{array}{l}\text { Birth } \\
\text { Order } \\
\text { Birthweight }(\mathrm{kg})\end{array}$ & $\begin{array}{c}\mathbf{1} \\
\mathbf{n}=177 \\
3.201\end{array}$ & $\begin{array}{c}1 \text { non-smokers } \\
\mathbf{n}=\mathbf{1 0 6} \\
3.262\end{array}$ & $\mathbf{1}$ & $\begin{array}{l}\text { smokers } \\
\mathrm{n}=71 \\
3.109\end{array}$ & $\begin{array}{c}\mathbf{2} \\
\mathbf{n}=174 \\
3.239\end{array}$ & $\begin{array}{c}2 \text { non-smokers } \\
\mathbf{n}=\mathbf{8 4} \\
3.325\end{array}$ & $\begin{array}{c}2 \text { smokers } \\
\mathrm{n}=90 \\
3.159\end{array}$ \\
\hline
\end{tabular}

Table III

Mean weight of low birthweight and pre-term infants shown against maternal smoking habit

Mean weight of all low birthweight babies (Kg)

Number pre-term

Mean weight of pre-term babies (Kg) than 37 weeks) by antenatal ultrasound or clinical assessment after delivery. Only three of these pre term low birth weight babies were born to non smoking mothers. (Table III).

\section{Discussion}

There are now many papers confirming Simpson's ${ }^{2}$ original reports that babies born to mothers who smoke are on average $200 \mathrm{gm}$ lighter than those born to non smoking mothers. It has also been shown ${ }^{3} \mathbf{a}, 3 \mathbf{b}$ that this difference in birth weight has long lasting effects on the physical and mental development of the child. These children also spend longer in hospital particularly in the first year of life.

Within the context of the British Army of the Rhine, with overstretched organic paediatric services and expensive local German facilities, the latter finding assumes great importance. The most encouraging finding in the present study is that less than half of the obstetric population of BAOR smoke at all, and of those that do, most do not smoke heavily. The most alarming finding in the current study is the disproportionate representation of smoking mothers in the low birth weight groups. This is a striking finding in both the incomplete retrospective study and in the, admittedly small, prospective study.
Despite recent attempts to fudge the issue by combining smoking with other socioeconomic problems $^{4}$ there is no real doubt that cigaretteo smoking in pregnancy has a direct, dose related. effect on birth weight. However, controversy still surrounds the mechanism by which this is achieved: D'Souza $^{5}$ has suggested that smoking is unlikely to effect foetal growth by causing under nutrition but this conclusion, following work on new born skin fold thickness, is not entirely justified. Lehtovirta and Forss ${ }^{6}$ have shown that following a standard cigarette there is an acute decrease in intervillous blood flow of about $28 \%$ which may persist for up to 15 minutes. Thus smoking 20 cigarettes a day causes a reduction in placental blood flow for up to five hours. More recently ${ }^{7}$ the same authors with others have shown that cigarette smoking caused observable abnormalities of foetal heart rate in normal term pregnancies which occured five to ten minutes after smoking a standard cigarette and persisted for up to 15 minutes. Superficially it would seem unlikely that carbon monoxide, which binds so firmly with adult haemoglobin, would cross the placenta in sufficient quantity to affect the foetus. However this is not so. Cole, Hawkins and Roberts ${ }^{8}$ have shown that foetal carboxyhaemoglobin levels can be 1.8 times greater than maternal levels at delivery. In addition, exposing foetal blood to carbon 
monoxide in vitro causes a shift to the left of the oxygen dissociation curve. There is therefore likely to a complex mechanism causing birth weight reduction involving maternal and foetal hypoxaemia as well as reduced placental blood flow, complicated by the pulsatile nature of these changes and differing excretion rates of maternal and foetal carbon monoxide.

Obviously further research is necessary to elucidate the precise mechanism by which smoking causes birth weight reduction. However, it must be obvious to all but to the most obdurate observer that one of the most significant steps which any pregnant woman can take to increase the chance of producing a healthy baby, is to give up smoking. This is nowhere so true as in the context of Service obstetric units which may be small and relatively isolated, with no direct access to local neonatal intensive care facilities. It is the duty of all concerned with obstetric care to put this message across as forcefully as possible.

\section{REFERENCES}

1 CROWDY J P, LEWTHWAITE C J. Smoking habits of young soldiers. A comparison betwen 1959 and 3

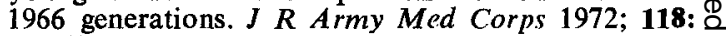
168-172.

2 SIMPSON W J. A preliminary report of cigarette $O$ smoking and the incidence of prematurity. $A m$ J Obstet Gynecol 1957; 73: 808-815.

3 DuNN $\mathrm{H}$ G et al. Maternal cigarette smoking during $\overrightarrow{\vec{F}}$ pregnancy and the child's subsequent deevlopment. क् (a) Physical growth to age $6 \frac{1}{2}$ years. Can J Pub Health 1976; 67: 499-505. (b) Neurological and 음 intellectual maturation to age $6 \frac{1}{2}$ years. Can $J \frac{\bar{\sigma}}{\bar{\alpha}}$ Pub Health 1977; 68: 43-50.

4 Cordozo L et al. Social and obstetric factors $\stackrel{\mathbb{Q}}{2}$ associated with smoking in pregnancy. $B r J$ Obstet ڤ Gynaecol 1982; 89: 622-627.

5 D'Souza S, Black P, Richards. B. Smoking in $\overrightarrow{0}$ pregnancy. Association with skinfold thickness, maternal weight gain and fetal size at birth. $\vec{\omega}$ Br Med J 1981; 82: 1661-1653.

6 LehtovirTA P, Forss $M$. The acute effect of smoking on intervillous blood flow of the placenta. Br J Obstet Gynaecol 1978; 85: 729-731.

7 LeHTovirTa P et al. The acute effects of smoking on fetal heart rate variability $B r J$ Obstet Gynaecol 0 1983; 90: 3-6.

8 Cole P, Hawkins L, Roberts D. Smoking duriag N pregnancy and its effects on the fetus. $B r J$ Obstot Gynaecol 1972; 79: 782-787.

\section{ACADEMIC ACHIEVEMENTS}

\section{MRCGP}

Maj N J Grundy-Wheeler, MB, BS, MRCS, LRCP, RAMC. Maj C Hannon, MB, BCh, DRCOG, RAMC. Capt B H Hodgson, MB, ChB, RAMC. Maj P H Lansley, MB, ChB, RAMC. Maj E L Malpass, MB, ChB, RAMC. Capt S McDonald, MB, BS, RAMC. Capt I McL Lyall, MB, ChB, RAMC. Capt V H Needham, MB, BS, RAMC. Capt R J F Owen-Jones, MB, BS, MRCS, LRCP, RAMC. Maj A Reid, MB, ChB, RAMC. Capt A J Riddell, BSc, MSc, ChB, RAMC. Capt R A Wells, MB, ChB, RAMC. Capt C A West, MB, ChB, RAMC.

\section{DRCOG}

Capt P M D Kennedy, MB, BS, MRCS, LRCP, RAMC.

MSc

Col D E Bradford, MB, ChB, FRCP, DTM\&H, L/RAMC.

(Health Administration.)

\section{Erratum}

The Editor apologises to Major J S Lloyd MB BS RAMC for any embarrassment caused by the N premature publication in the February 1983 issue of the Journal of his passing the MRCP. 